\title{
Different effects of low-dose transdermal and oral oestrogen therapy on procarboxy- peptidase $U$, an inhibitor of fibrinolysis, in healthy postmenopausal women: A randomised, placebo-controlled study
}

\section{Dear Sir,}

The effect that oestrogen therapy exerts on markers of coagulation and fibrinolysis in postmenopausal women depends on the route of administration (oral or transdermal) (1-3) and whether or not a progestogen is added (1-5). Recently, Scarabin et al. found that transdermal oestrogen therapy, in contrast to oral therapy, is not associated with an elevated risk of venous thromboembolism (6). This indicates that different forms of hormone therapy not only differentially affect the balance of markers of coagulation and fibrinolysis but also have different effects on the risk of venous thromboembolism. In addition, the early increased risk of coronary heart disease observed in postmenopausal women using oral hormone therapy $(7,8)$ has been thought to be related to procoagulatory changes.

Procarboxypeptidase U (proCPU, EC 3.4.17.20), also known as thrombin-activatable fibrinolysis inhibitor (TAFI), is considered to be a link between coagulation and fibrinolysis (9-11). During coagulation and fibrinolysis the active enzyme, carboxypeptidase $\mathrm{U}(\mathrm{CPU})$ is generated from proCPU (12). CPU exerts its antifibrinolytic effect by removing $\mathrm{C}$-terminal lysine residues from partially degraded fibrin (11), thereby abrogating the enhanced plasminogen activation and preventing an acceleration of fibrinolysis. Elevated levels of proCPU have been found to be a mild risk factor for venous thrombosis (13) and were observed in patients with angina pectoris (14).

Data on the effect of oral hormone therapy on proCPU levels are scarce and inconclusive, whereas no data are available on the effect of transdermal treatment. In the present study, we intended to elucidate the role of the route of oestrogen administration and the effect of the addition of the progestogen gestodene to oral oestradiol on proCPU levels.

The design of this study was published previously (2, 3, 15-18). Briefly, in this randomised, placebo-controlled, doubleblind, double-dummy, multicentre study, 152 healthy hysterectomised postmenopausal women aged 45 to 65 years received daily either placebo $(n=49)$, or transdermal $17 \beta$-oestradiol $\left(E_{2}\right)$ $50 \mu \mathrm{g}\left(\right.$ Climara $^{\circledR}, \mathrm{tE}_{2}$ group, $\left.\mathrm{n}=33\right)$, or oral $\mathrm{E}_{2} 1 \mathrm{mg}\left(\mathrm{oE}_{2}\right.$ group, $\mathrm{n}=37)$, or oral $\mathrm{E}_{2} 1 \mathrm{mg}$ combined with gestodene $25 \mu \mathrm{g}\left(\mathrm{oE}_{2}+\mathrm{G}\right.$

\footnotetext{
Correspondence to:

M.J. van der Mooren, M.D., PhD,

Department of Obstetrics \& Gynaecology

VU University Medical Center

PO Box 7057, 1007 MB Amsterdam

The Netherlands

Tel.: +3। 2044432 44, Fax: +3I 204444422 .

E-mail:mj.vandermooren@VUmc.nl

Received July 26, 2004

Accepted after resubmission December 28, 2004

Grant support:

This work was supported by research grants from the Netherlands Heart Foundation (grant 95.20I), Biocare Foundation (grant 96.3I2), and Schering AG (Berlin, Germany, grant 96.083). J.R. Leurs was a research assistant of the Fund for Scientific Research Flanders (FWO-Vlaanderen).
}

Thromb Haemost 2005; 93: 620-2 group, $n=33$ ) for thirteen 28-day treatment cycles, followed by four cycles of placebo for each group. The investigation conformed to the principles outlined in the Declaration of Helsinki. Institutional Review Boards of all participating centres approved the protocol. Written informed consent was obtained from each participant before entry into the study.

Venous plasma samples were collected at baseline and in cycles 4,13 and 17 and stored at $-80^{\circ} \mathrm{C}$ until analysis. Samples of 146 participants were available for analysis. Plasma proCPU concentrations were determined by converting the zymogen to its active form and subsequently measuring the carboxypeptidase activity with a colorimetric assay $(5,19,20)$. The mean intra-assay coefficient of variation was $3.7 \%$.

Statistical analysis was performed using the Statistical Package for the Social Sciences PC + 9.0 (SPSS Inc., Chicago, Illinois). ProCPU concentrations are given as mean \pm standard deviation (SD) and the individual percentage changes from baseline as mean with $95 \%$ confidence interval (CI). Standard parametric tests were performed. Analyses of covariance (ANCOVA) for repeated measurements, with the baseline concentrations of proCPU and serum oestradiol as constant covariates, were used for comparisons among and between the groups.

At baseline, no significant differences were found between the groups in either proCPU levels or demographic characteristics (age, body mass index (BMI), blood pressures, number of smokers, serum cholesterol, FSH and oestradiol levels). The women had an age of $54.6 \pm 4.5$ years (mean \pm SD) and a BMI of $25.6 \pm 2.9 \mathrm{~kg} / \mathrm{m}^{2}$ (mean $\left.\pm \mathrm{SD}\right)$.

In cycle 13, proCPU was significantly decreased in the $\mathrm{tE}_{2}$ and $\mathrm{oE}_{2}+\mathrm{G}$ group compared to placebo $(\mathrm{P}<0.001)$, but not in the $\mathrm{oE}_{2}$ group (Table). The mean percentage changes from baseline versus placebo were $-8.6 \%[95 \% \mathrm{CI}-12.1$ to $-5.1 \%]$ in the $\mathrm{tE}_{2}$ group and $-7.9 \%[95 \% \mathrm{CI}-10.9$ to $-5.0 \%]$ in the $\mathrm{oE}_{2}+\mathrm{G}$ group. The decreases were already apparent in cycle 4 . Changes in the $\mathrm{tE}_{2}$ and $\mathrm{oE}_{2}+\mathrm{G}$ group differed significantly from the changes in the $\mathrm{oE}_{2}$ group. After four cycles of wash-out, when compared to baseline and placebo, the decrease observed in the $\mathrm{oE}_{2}+\mathrm{G}$ group persisted $(-4.6 \%$ [95\% CI -7.9 to $-1.3 \%])$.

In earlier randomised controlled trials and in the present study it was observed that neither unopposed oral $17 \beta$-oestradiol in a dosage of 1 or $2 \mathrm{mg}$ daily (5) nor oral oestrogens combined with dydrogesterone (5), medroxyprogesterone acetate (20), or norethisterone acetate (21) changed proCPU levels. In contrast, decreased plasma proCPU levels were observed during transdermally administered oestradiol $50 \mu \mathrm{g}$ daily and during oral oestradiol combined with the progestogens gestodene or trimegestone (5). Taken together, data from randomised controlled trials indicate that both the route of administration and the addition of different progestogens play a role in the effect of oestrogens on plasma proCPU. Consequently, this will have differential effects on the haemostatic balance and, therefore, may differentially affect clinical venous and arterial thromboembolic risk. However, results from the present study are puzzling, since 
Table: Plasma procarboxypeptidase $U$ concentrations.

\begin{tabular}{|c|c|c|c|c|c|c|c|c|c|c|c|c|}
\hline & $\mathbf{N}$ & Baseline & cycle 4 & cycle 13 & ANCOVA $\ddagger$ & ANCOVA & $\% \Delta 0-13$ & $\mathbf{N}$ & cycle 17 & ANCOVA $^{\#}$ & ANCOVA & $\% \Delta 0-17$ \\
\hline Placebo & 47 & $619 \pm 80$ & $625 \pm 72$ & $633 \pm 92$ & $<0.001$ & & & 40 & $624 \pm 84$ & 0.001 & & \\
\hline $\mathrm{tE}_{2}$ & 32 & $631 \pm 100$ & $601 \pm 90$ & $591 \pm 97$ & & $<0.001$ & $-8.6(-12.1 \text { to }-5.1)^{* *}$ & 29 & $642 \pm 94$ & & 0.001 & $-0.6(-4.1$ to 2.9$)$ \\
\hline $\mathrm{oE}_{2}$ & 37 & $659 \pm 85$ & $649 \pm 99$ & $654 \pm 97$ & & 0.13 & $-3.2(-6.5$ to 0.2$)$ & 36 & $659 \pm 93$ & & 0.27 & $-2.2(-5.6$ to 1.2$)$ \\
\hline $\mathrm{oE}_{2}+\mathrm{G}$ & 30 & $643 \pm 115$ & $594 \pm 111$ & $620 \pm 102$ & & $<0.001$ & $-7.9(-10.9$ to -5.0$)$ ** & 29 & $637 \pm 92$ & & $<0.001$ & $-4.6(-7.9 \text { to }-1.3)^{*}$ \\
\hline
\end{tabular}

Concentrations $(\mathrm{U} / \mathrm{L})$ are given as mean $\pm \mathrm{SD}$

¥ANCOVA with the baseline values of proCPU and oestradiol as constant covariate for among-group differences over the 13-cycle study period.

\#ANCOVA over the I3-cycle study period: treatment versus placebo. In addition, significant differences were found between the $t E_{2}$ and $\circ E_{2}$ group $(P<0.00 \mathrm{I})$ and between the o $\mathrm{E} E_{2}$ and o $E_{2}+G$ group $(P<0.00 \mathrm{I})$. $\% \Delta$, Mean $(95 \% \mathrm{Cl})$ of the individual percentage changes from baseline compared to placebo at cycle I 3 and at cycle 17 . $* \mathrm{P}<0.05$ and $* * \mathrm{P}<0.00 \mathrm{I}$.

\#ANCOVA with the baseline values of proCPU and oestradiol as constant covariate for among-group differences over the study period from cycle 13 to cycle 17 .

\#ANCOVA from cycle 13 to cycle 17 (after correction for baseline values): treatment versus placebo. In addition, significant differences were found between the $t E_{2}$ and o $E_{2}$ group $(P<0.05)$ and between the o $E_{2}$ and $o E_{2}+G$ group $(P<0.05)$.

$\mathrm{N}=$ number of participants of whom data were analysed

previous studies clearly showed that orally but not transdermally administered oestrogens increase fibrinolysis.

Since the proenzyme proCPU is mainly produced in the liver, the observed difference in effect of orally and transdermally administered unopposed oestrogen may be the consequence of avoiding the hepatic first-pass effects in the latter. Besides a decreased production, the observed reductions in plasma proCPU levels can be the result of an increase in the conversion of pro$\mathrm{CPU}$ to active $\mathrm{CPU}$ as well. The activation of proCPU to $\mathrm{CPU}$ occurs during coagulation and fibrinolysis by plasmin, thrombin, and by a complex of thrombin with thrombomodulin (22). Therefore, effects of transdermal oestradiol and oral oestradiol combined with gestodene on these haemostatic factors may have contributed to our observations.

In contrast to oral postmenopausal hormone therapy, transdermally administered hormone therapy is not associated with an increased risk of venous thrombosis (6). The risk of venous thrombosis depends, in part, on the balance between markers of coagulation and fibrinolysis. Since plasma proCPU plays a role in this balance as well, differences in effect of the two routes of administration on proCPU levels as observed in our study may therefore contribute to the difference in venous thrombosis risk in users of oral and transdermal hormone therapy.

In elderly women, oral combined oestrogen plus progestogen therapy is possibly associated with a slightly early increased risk for coronary heart disease (CHD) $(7,8)$, whereas a non-significant increased risk of CHD was observed in elderly women using a high dose of transdermal oestradiol (23). Interestingly, recent data suggest a protective effect of oral unopposed oestrogen therapy in postmenopausal women aged 50-59 years (24). Contradictory results have been found in trials investigating the association of proCPU levels and arterial thrombotic events $(14,25)$.
This might be the consequence of differences in study populations and the use of different assays (25). We want to stress that the reductions in proCPU in relatively young postmenopausal women as observed in our study should not be extrapolated to elderly women who are at increased CHD risk during oral combined oestrogen plus progestogen therapy.

In conclusion, transdermal unopposed oestradiol reduced plasma proCPU levels whereas oral unopposed oestradiol did not. Oral oestradiol combined with gestodene also lowered proCPU levels. A reduction in proCPU may contribute to increased fibrinolysis.

\section{Acknowledgements}

The authors wish to thank Mrs H. Kessel, M.D. for her excellent logistical assistance and recruitment of participants (VU University Medical Center, Amsterdam), Mrs Y. Sim for her technical assistance (University of Wilrijk, Antwerp) and the following investigators who participated in this study: J. M.W.M. Merkus, M.D., PhD, C.P.T. Schijf, M.D., Mrs C.F. van Heteren, M.D., J.M. Smeenk, M.D. (University Medical Centre Sint Radboud, Nijmegen); M.V.A.M. Kroeks, M.D., PhD (Diakonessenhuis, Utrecht); H.R. Franke, M.D., PhD (Medisch Spectrum Twente Hospital Group, Enschede); and all women who participated in the study.

\section{Marinka S. Post', Judith R. Leurs², Marius J. van der Mooren', W. Marchien van Baal', Dirk F. Hendriks², Coen D.A. Stehouwer ${ }^{3}$, Peter Kenemans ${ }^{\prime}$ \\ Project 'Ageing Women' and the Institute for Cardiovascular Research-Vrije Universiteit (ICaR-VU), Departments of 'Obstetrics \& Gynaecology and ${ }^{3}$ Internal Medicine, VU University Medical Center, Amsterdam, and ${ }^{3}$ Internal Medicine, Maastricht University, Maastricht, The Netherlands; ${ }^{2}$ Department of Medical Biochemis- try, University of Antwerp, Wilrijk, Belgium}

\section{References}

1. Lowe GDO, Upton MN, Rumley A, et al. Different effects of oral and transdermal hormone replacement therapies on factor IX, APC resistance, t-PA, PAI and C-reactive protein. Thromb Haemost 2001; 86: 550-6. 2. Post MS, Thomassen MCLGD, van der Mooren MJ, et al. Effect of oral and transdermal estrogen replacement therapy on hemostatic variables associated with venous thrombosis: a randomized, placebo-controlled study in postmenopausal women. Arterioscler Thromb Vasc Biol 2003; 23: 1116-21.
3. Post MS, van der Mooren MJ, van Baal WM, et al Effects of low-dose oral and transdermal estrogen replacement therapy on hemostatic factors in postmenopausal women: a randomized placebo-controlled study. Am J Obstet Gynecol 2003; 189: 1221-7.

4. Van Baal WM, Emeis JJ, van der Mooren MJ, et al Impaired procoagulant-anticoagulant balance during hormone replacement therapy? A randomised, placebo-controlled 12-week study. Thromb Haemost 2000; 83: $29-34$
5. Post MS, Hendriks DF, van der Mooren MJ, et al. Oral oestradiol/trimegestone replacement reduces procarboxypeptidase U (TAFI): a randomized placebocontrolled 12-week study in early postmenopausal women. J Intern Med 2002; 251: 245-51.

6. Scarabin PY, Oger E, Plu-Bureau G. Differential association of oral and transdermal oestrogen-replacement therapy with venous thromboembolism risk. Lancet 2003; 362: 428-32. 
7. Hulley S, Grady D, Bush T, et al. Randomized trial of estrogen plus progestin for secondary prevention of coronary heart disease in postmenopausal women. JAMA 1998; 280: 605-13.

8. Manson JE, Hsia J, Johnson KC, et al. Estrogen plus progestin and the risk of coronary heart disease. N Engl J Med 2003; 349: 523-34.

9. Hendriks DF, Scharpe SS, van Sande M, et al. Characterisation of a carboxypeptidase in human serum distinct from carboxypeptidase N. J Clin Chem Clin Biochem 1989; 27: 277-85.

10. Bajzar L, Manuel R, Nesheim ME. Purification and characterization of TAFI, a thrombin-activable fibrinolysis inhibitor. J Biol Chem 1995; 270: 14477-84.

11. Wang W, Boffa MB, Bajzar L, et al. A study of the mechanism of inhibition of fibrinolysis by activated thrombin-activable fibrinolysis inhibitor. J Biol Chem 1998; 273: 27176-81.

12. Leurs J, Wissing BM, Nerme V, et al. Different mechanisms contribute to the biphasic pattern of carboxypeptidase U (TAFIa) generation during in vitro clot lysis in human plasma. Thromb Haemost 2003; 89: 264-71.

13. Van Tilburg NH, Rosendaal FR, Bertina RM Thrombin activatable fibrinolysis inhibitor and the risk for deep vein thrombosis. Blood 2000; 95: 2855-9.

14. Silveira A, Schatteman KA, Goossens FJ, et al. Plasma procarboxypeptidase $\mathrm{U}$ in men with sympto- matic coronary artery disease. Thromb Haemost 2000; 84: 364-8

15. Post MS, van der Mooren MJ, Stehouwer CDA, et al. Effects of transdermal and oral oestrogen replacement therapy on $\mathrm{C}$-reactive protein levels in postmenopausal women: a randomised, placebocontrolled study. Thromb Haemost 2002; 88: 605-10.

16. Smolders RGV, van der Mooren MJ, Teerlink T, et al. A randomized placebo-controlled study of the effect of transdermal vs. oral estradiol with or without gestodene on homocysteine levels. Fertil Steril 2003; 79: 261-7.

17. Vogelvang TE, van der Mooren MJ, Kamp O, et al. Effects of oral and transdermal low-dose estrogen therapy on echocardiographic parameters of cardiac function. Fertil Steril 2003; 80: 546-53.

18. Hemelaar M, van der Mooren MJ, Mijatovic V, et al. Oral, more than transdermal, estrogen replacement therapy improves lipids and lipoprotein(a) in postmenopausal women: a randomized, placebo-controlled study. Menopause 2003; 10: 550-8.

19. Schatteman KA, Goossens FJ, Leurs JR, et al. Fast homogeneous assay for plasma procarboxypeptidase U. Clin Chem Lab Med 2001; 39: 806-10.

20. Vogelvang TE, Leurs JR, van der Mooren MJ, et al. Raloxifene reduces procarboxypeptidase $U$, an antifibrinolytic marker. A 2-year randomized, placebo-con- trolled study in healthy early postmenopausal women. Menopause 2004; 11: 110-5

21. Bladbjerg EM, Madsen JS, Kristensen SR, et al. Effect of long-term hormone replacement therapy on tissue factor pathway inhibitor and thrombin activatable fibrinolysis inhibitor in healthy postmenopausa women: a randomized controlled study. J Thromb Haemost 2003; 1: 1208-14.

22. Leurs J, Nerme V, Sim Y, et al. Carboxypeptidase U (TAFIa) prevents lysis from proceeding into the propagation phase through a threshold-dependent mechanism. J Thromb Haemost 2004; 2: 416-23.

23. Clarke SC, Kelleher J, Lloyd-Jones H, et al. A study of hormone replacement therapy in postmenopausal women with ischaemic heart disease: the Papworth HRT Atherosclerosis Study. Br J Obstet Gynaecol 2002; 109: 1056-62.

24. Anderson GL, Limacher M, AssafAR, et al. Effects of conjugated equine estrogen in postmenopausa women with hysterectomy: the Women's Health Initiative randomized controlled trial. JAMA 2004; 291 1701-12.

25. Juhan-Vague I, Morange PE, Aubert H, et al. Plasma thrombin-activatable fibrinolysis inhibitor antigen concentration and genotype in relation to myocardial infarction in the north and south of Europe. Arterioscler Thromb Vasc Biol 2002; 22: 867-73.

\section{Rebuttal: A problem of calibration in the paper 'Point of care monitoring of oral anticoagulant therapy in children'}

\section{Dear Sir}

We read with interest the paper by Ignjatovic and colleagues (1) and were encouraged to learn about their efforts to improve the quality of their service to children and young people.

We were disturbed, however, at the way in which the study was carried out and concerned about its conclusions. In particular, the idea that the laboratory venous method of INR determination should be deemed the "gold standard" is an extraordinary assertion. The laboratory method described was an ACL 100 with Instrumentation Laboratory's ILTest PT Fibrinogen. The laboratory relied on the International Sensitivity Index (ISI) assigned to the reagent by the manufacturer. No attempt was

\section{Correspondence to:}

Ken Stevenson

Anticoagulation and Haematology Research Unit

Wythenshawe Hospital

Manchester M23 9LT

UK

Tel.: +44 I6I 29I 4747, Fax +44 29I 4749

E-mail ken.stevenson@smuht.nwest.nhs.uk

Received November 5, 2004

Accepted November 17, 2004

Thromb Haemost 2005; 93: 622 made to determine a local system ISI. The authors used as justification a paper by Hobbs et al. (2) describing a study to compare INR measurements in hospital laboratories and primary care settings. Hobbs et al. used three hospitals and applied the term "gold standard" to the one which had taken the trouble to assign a system ISI to their combination of coagulometer and thromboplastin reagent. We do not believe that these authors were suggesting that any laboratory INR method can be a "gold standard"!

We feel that the only proper way to undertake studies of this sort must be to use manual prothrombin time testing with an International Reference Preparation (IRP) as the "gold standard", or, at least, to perform a system ISI calibration of the laboratory method to align it to the WHO system. Shiach et al. (3) described the ideal approach in a comparison study by performing system ISI for both laboratory and point of care testing. This should surely be the model for similar studies.

\section{Steven Craig, David Leeming, Allan Sidebotham, Ken Stevenson Anticoagulation and Haematology Research Unit, South Manchester University Hospitals Trust, Wythenshawe Hospital, Manchester, UK}

\section{References}

1. Ignjatovic V, Barnes $\mathrm{C}$, Newall F, et al. Point of care monitoring of oral anticoagulant therapy in children: comparison of CoaguChek Plus and Thrombotest methods with venous international normalised ratio. Thromb Haemost 2004; 92: 734-7.
2. Hobbs F, Fitzmaurice D, Murray E, et al. Is the international normalised ratio (INR) reliable? A trial of comparative measurements in hospital laboratory and primary care settings. J Clin Pathol 1999; 52: 494-7.
3. Shiach C, Campbell B, Poller L, et al. Reliability of point-of-care prothrombin time testing in a community clinic: a randomised crossover comparison with hospital laboratory testing. Br J Haematol 2002; 119; 370-5. 